ARTICLE

https://doi.org/10.1057/s41599-019-0271-4

\title{
Cultural change in animals: a flexible behavioural adaptation to human disturbance
}

\author{
Thibaud Gruber (1) ${ }^{1,2}$, Lydia Luncz ${ }^{2}$, Julia Mörchen ${ }^{3}$, Caroline Schuppli ${ }^{4}$, Rachel L. Kendal ${ }^{5,7}$ \& \\ Kimberley Hockings 6,7
}

\begin{abstract}
In recent decades, researchers have increasingly documented the impact of anthropogenic activities on wild animals, particularly in relation to changes in behaviour. However, whether human-induced behavioural changes in wildlife may be considered evidence of cultural evolution remains an open question. We explored whether behavioural responses to different types of human activities in species already known to display behaviour transmitted through social learning, particularly non-human primates (NHPs), are suggestive of cultural evolution in the wild. Results indicate that human influence on NHP cultural repertoires includes the modification and disappearance of existing cultural traits, as well as the invention of novel traditions with the potential to become cultural. These examples are found mostly in the domain of food acquisition, where animals modify their diet to include new resources, and adopt novel foraging strategies to avoid humans. In summary, this paper suggests that human activities can act as a catalyst for cultural change in animals, both in terms of threatening existing traditions and fostering new ones. The current situation may echo environmental changes thought to have triggered major behavioural adaptations in our own evolutionary history and thus be useful for research on human cultural evolution. As wildlife is increasingly exposed to humans and their activities, understanding how animal behaviour patterns and cultures are impacted and change in response to anthropogenic factors is of growing conservation importance.
\end{abstract}

\footnotetext{
${ }^{1}$ University of Geneva, Geneva, Switzerland. ${ }^{2}$ University of Oxford, Oxford, UK. ${ }^{3}$ Max Planck Institute for Evolutionary Anthropology and University of Leipzig, Leipzig, Germany. ${ }^{4}$ University of Zürich, Zürich, Switzerland. ${ }^{5}$ Durham University, Durham, UK. ${ }^{6}$ University of Exeter, Exeter, UK. ${ }^{7}$ These authors contributed equally: Rachel L. Kendal, Kimberley Hockings Correspondence and requests for materials should be addressed to

T.G. (email: thibaud.gruber@gmail.com)
} 


\section{Introduction}

here has been a recent surge of interest in studying the impact of human activities on wild animal populations. Many species and/or populations cannot avoid humans and must therefore display behavioural strategies to cope with the ever-growing human disturbance in their environment (Candolin and Wong, 2012, McLennan et al., 2017, Barrett et al. 2019). This paper investigates animal, in particular non-human primate (NHP), potentially cultural responses to human activities (e.g., agriculture, hunting, road development). When these behavioural changes are deemed cultural (innovation is made by one or a limited number of individuals and is subsequently learned by others through social means (Fragaszy and Perry, 2003)), it suggests that humans can drive cultural change or cultural evolution (used synonymously; see below and Lamon et al., 2018; Mesoudi and Thornton, 2018) in other species. Our aim here is to collect behavioural adaptations to human disturbance that have possibly, or have the potential to, spread culturally in a given animal population.

Although numerous species exhibit behavioural variations in response to humans and their activities (see review in Barrett et al., 2019), our focus is on NHPs because of our joint expertise, but also because NHPs fulfil an unusual conglomerate of factors relevant to this question: (1) many NHP species are large-bodied and slow reproducing, long-lived species (Charnov and Berrigan, 1993, van Schaik et al., 2006) for which behavioural flexibility is the main (if not the only) way to respond quickly to environmental changes; (2) there is an extensive literature on NHP social learning and culture in both captive and wild settings, with some records spanning over 50 years on the same populations (Whiten et al., 1999, Kawai, 1965, Hirata et al., 2001), and with growing evidence that wild NHPs need to learn their skills during development through socially aided learning (Schuppli et al., 2016, Lamon et al., 2017); (3) NHPs provide the opportunity to discuss possible drivers of human cultural evolution through homology (Whiten et al., 2010). Nevertheless, there are also many examples of non-primate cultures that are impacted by humans and are possibly subject to cultural evolution (Brakes et al., 2019). Rather than an exhaustive catalogue of possible animal cultural behaviours that might be impacted by humans, this piece provides a theoretical framework for understanding how humans may impact non-human cultures, and calls for conservation strategies to take account of behavioural diversity to ensure that 'cultural units' (i.e., identifiable patterns of behaviour that have a socially learnt origin) are preserved (Whitehead, 2010, Greggor et al., 2014).

\section{Evidence for flexible behavioural adaptation to human disturbance}

Some species cope with human disturbance through genetic adaptation (e.g., Marnocha et al., 2011). However, for species with slow life histories genetic adaptation is difficult to achieve over short time periods. Another strategy in response to locally changing conditions (e.g., anthropogenic food sources, McLennan and Hockings, 2014) is proximately induced behavioural flexibility (Sih et al., 2011), that is "behavioural responses to changing local conditions, reflecting solutions to ecological or social problems" (p215, Hockings et al., 2015a). A prime example of behavioural flexibility in animals is the documented adaptation to ongoing human-provoked climate change (Beever et al., 2017). If such climate-change-led adaptations fit the cultural criteria, this will constitute strong evidence that humans alter animal cultures indirectly. However, because there is currently limited evidence of the connection between climate change and animal cultures (but see Wild et al. (2019) who report that culture may alleviate the effects of climate variation in bottlenose dolphins (Tursiops aduncus)) and specifically NHP cultures, our focus will be on behavioural adaptations in response to direct encounters with humans or human activities. Habitat loss and fragmentation have been shown to reduce movements in numerous mammal species worldwide (Tucker et al., 2018), with many mammals (e.g., elephants, (Loxodonta africana, Bates et al., 2007)) or chimpanzees (Pan troglodytes, Hicks et al., 2013)) modifying their behaviour to avoid contact with humans. However, avoidance behaviour can be the result of a variety of processes (e.g., predator or threat avoidance, neophobia), which are not specifically connected to human activity or necessarily learned. An example of direct avoidance of humans is the development of nocturnal cropforaging behaviour in one community of chimpanzees at Sebitoli in Uganda (Krief et al., 2014). Such behavioural responses, far from being isolated (see review in McLennan et al., 2017 and Table 1), suggest that novel behaviours in wild NHPs and other species may enter their behavioural repertoire as a result of human activities. However, it is important to determine whether these behavioural modifications are cultural.

\section{Culture and cultural change}

The analysis of culture as a biological and evolutionary phenomenon (Boyd and Richerson, 1985), and the existence of socially transmitted behavioural variation between groups or subgroups of the same species in non-humans, reminiscent of human culture (Laland and Galef, 2009), is now well accepted. Reports of cultural transmission in non-humans, including in Japanese macaques (Macaca fuscata, Imanishi, 1952), great tits (Parus major, Fisher and Hinde, 1949) and chimpanzees (Goodall, 1973), have launched a strong debate on the nature of culture in animals and how it compares to humans (Tomasello 1990, Galef, 1992, Laland and Galef, 2009). A cultural species displays patterns of behaviour (or 'traditions') acquired in part through socially aided learning processes (Fragaszy and Perry, 2003). Classically, if controversially (Laland et al., 2009), variation in behaviour between groups of the same species is used to detect such social learning by excluding genetic or ecological factors as underlying sources of the variation (the exclusion method: Whiten et al. 1999). A major concern is that the exclusion method can generate false positives or negatives in part because of our inability to isolate all relevant ecological factors that come into play in the appearance of a behaviour (Laland and Janik, 2006); in addition, the method does not provide direct evidence for social learning itself (Kendal et al., 2010b). Such criticism has in turn led to a wealth of studies aiming to further investigate ecological drivers of NHP behaviour (Möbius et al., 2008, Gruber et al., 2012, Spagnoletti et al., 2012, Langergraber et al., 2010, Schöning et al., 2008, Krützen et al., 2007) and create diverse methods for identifying social learning in wild animals, particularly NHPs (Luncz and Boesch, 2014, Hobaiter et al., 2014, Aplin et al. 2015, Allen et al., 2013, Kendal et al., 2010a, Hoppitt and Laland, 2011). The resulting evidence has allowed the debate to shift from the existence of non-human cultures to the issue of whether nonhumans possess cumulative cultures, that is, the process by which cultural groups progressively improve their behavioural traits through innovative modifications and social transmission over generations (Mesoudi and Thornton, 2018, Dean et al., 2014). While recent findings suggest that non-human animals are able to adopt increasingly efficient or complex techniques to meet their goals (Sanz et al., 2009, St Clair et al., 2018, Sasaki and Biro, 2017, Lamon et al., 2018), data on cumulative cultural evolution in wild animals remain controversial and lacking (Dean et al., 2014). Although not universally accepted (Mesoudi and Thornton, 2018), the ratcheting up of complexity or efficiency of a 
Table 1 Possible non-human primate cultural variants impacted by human influence

\begin{tabular}{|c|c|c|c|c|c|}
\hline Human influence & Species & Specific disturbance & Response & Reference & $\begin{array}{l}\text { Evidence for cultural } \\
\text { behaviour }\end{array}$ \\
\hline \multirow[t]{3}{*}{$\begin{array}{l}\text { Human presence in the } \\
\text { environment }\end{array}$} & $\begin{array}{l}\text { Chimpanzee (Pan } \\
\text { troglodytes) }\end{array}$ & Increased hunting pressure & Decrease in ground nesting $(D)^{a}$ & Tagg et al. (2013) & $\begin{array}{l}\text { Matsuzawa, and Yamakoshi } \\
\text { (1996) }\end{array}$ \\
\hline & & & Deactivation of snares (I) & $\begin{array}{l}\text { Ohashi and } \\
\text { Matsuzawa (2010) }\end{array}$ & $\begin{array}{l}\text { Ohashi and Matsuzawa } \\
(2010)\end{array}$ \\
\hline & $\begin{array}{l}\text { Long-tailed macaques } \\
\text { (Macaca fascicularis) }\end{array}$ & $\begin{array}{l}\text { Presence of local farm dogs at foraging } \\
\text { sites at the shore }\end{array}$ & Decrease of stone tool use (D) & Gumert et al. (2013) & $\operatorname{Tan}(2017)$ \\
\hline \multirow[t]{10}{*}{$\begin{array}{l}\text { Introduced and novel } \\
\text { food items }\end{array}$} & $\begin{array}{l}\text { Orang-Utans (Pongo } \\
\text { pygmaeus) }\end{array}$ & Oil palm mono cultures & $\begin{array}{l}\text { Dispersal into mature plantations, use oil } \\
\text { palm trees for nesting, and feeding on } \\
\text { mature fruits }(M)\end{array}$ & $\begin{array}{l}\text { Ancrenaz et al. } \\
\text { (2014) }\end{array}$ & van Schaik et al. (2003) \\
\hline & $\begin{array}{l}\text { Chimpanzee (Pan } \\
\text { troglodytes) }\end{array}$ & $\begin{array}{l}\text { Newly human-introduced trees or crops } \\
\text { for animals living in the vicinity of human } \\
\text { settlements }\end{array}$ & $\begin{array}{l}\text { Crop-feeding (I) } \\
\text { Emergence of leaf tools used for the } \\
\text { consumption of Raphia palm wine }(M)\end{array}$ & $\begin{array}{l}\text { McLennan and } \\
\text { Hockings (2014) }\end{array}$ & Whiten et al. (1999) \\
\hline & & & Crop-feeding during the night (M) & Krief et al. (2014). & $\begin{array}{l}\text { Hockings et al. } \\
(2015 a, 2015 b)\end{array}$ \\
\hline & $\begin{array}{l}\text { Chimpanzee (Pan } \\
\text { troglodytes) }\end{array}$ & $\begin{array}{l}\text { Proliferation of natural fig species due to } \\
\text { controlled forest poisoning and } \\
\text { introduction of non-native species in the } \\
\text { core area }\end{array}$ & Loss of stick tool use (D) a & Gruber (2013) & Gruber et al. (2009) \\
\hline & $\begin{array}{l}\text { Chimpanzee (Pan } \\
\text { troglodytes) }\end{array}$ & Newly human-introduced plant species & Nest manufacture $(\mathrm{M})$ & $\begin{array}{l}\text { McCarthy et al. } \\
\text { (2017) }\end{array}$ & $\begin{array}{l}\text { Matsuzawa, Yamakoshi } \\
\text { (1996) }\end{array}$ \\
\hline & $\begin{array}{l}\text { Japanese macaques } \\
\text { (Macaca fuscata) }\end{array}$ & $\begin{array}{l}\text { Introduction of potatoes and corn (though } \\
\text { direct provisioning) }\end{array}$ & Food washing (I) & Kawai (1965) & Schofield et al. (2018) \\
\hline & $\begin{array}{l}\text { Japanese macaques } \\
\text { (Macaca fuscata) }\end{array}$ & $\begin{array}{l}\text { Visitor (e.g., fishermen) leaving raw fish to } \\
\text { dry or providing on Koshima island }\end{array}$ & Consumption of raw fish (I) & Watanabe (1989) & Watanabe (1989) \\
\hline & $\begin{array}{l}\text { Japanese macaques } \\
\text { (Macaca fuscata) }\end{array}$ & $\begin{array}{l}\text { The influence of the occurrence and } \\
\text { frequency of food provisioning on object- } \\
\text { directed play behaviour in Japanese } \\
\text { macaques }\end{array}$ & Stone handling $(\mathrm{M})$ & Leca et al. (2008) & Leca et al. (2008) \\
\hline & $\begin{array}{l}\text { Long-tailed macaques } \\
\text { (Macaca fascicularis) }\end{array}$ & $\begin{array}{l}\text { Co-occurrence of provisioning and co- } \\
\text { habitation with humans at a temple }\end{array}$ & $\begin{array}{l}\text { Innovation and diffusion of token- } \\
\text { mediated exchange between humans } \\
\text { and long-tailed macaques (I) }\end{array}$ & $\begin{array}{l}\text { Brotcorne et al. } \\
\text { (2017) }\end{array}$ & Brotcorne et al. (2017) \\
\hline & $\begin{array}{l}\text { Long-tailed macaques } \\
\text { (Macaca fascicularis) }\end{array}$ & Introduction of oil palm trees & Development of oil palm nut-cracking (I) & Luncz et al. (2017) & $\operatorname{Tan}(2017)$ \\
\hline \multirow[t]{2}{*}{$\begin{array}{l}\text { Habitat alterations and/or } \\
\text { decrease in natural foods }\end{array}$} & $\begin{array}{l}\text { Chimpanzee (Pan } \\
\text { troglodytes) }\end{array}$ & $\begin{array}{l}\text { Disappearance of naturally occurring } \\
\text { decaying Raphia that provided specific } \\
\text { nutrients }\end{array}$ & Emergence of moss sponging $(M)$ & Reynolds et al. (2015) & Hobaiter et al. (2014) \\
\hline & Gibbons & Forest fire smoke & Decrease in song and call pattern (D) ${ }^{a}$ & Cheyne (2010) & Koda et al. (2013) \\
\hline \multicolumn{6}{|c|}{$\begin{array}{l}\text { Note: Invention is defined as novel behaviour resulting from independent asocial learning, i.e., there is no immediate prior information (that may be socially learned) from which the impetus for the } \\
\text { innovation directly emerges, while Modification is defined as a novel behaviour resulting from asocial modification of an existing behaviour or evaluation of prior information (that may have been gleaned } \\
\text { socially). See Carr et al. (2016) for additional definitions. Further we posit that incorporation of a new plant part (e.g., tuber) or food type (e.g., fish) previously not eaten would be invention, but that } \\
\text { consumption of a new fruit species by a species that already eats fruit is modification } \\
D \text { Decrease of a behaviour pattern, I invention innovation, } M \text { modification innovation } \\
\text { adenotes cases that are more speculative in our current list }\end{array}$} \\
\hline
\end{tabular}

behavioural trait (Tennie et al. 2009) remains a major criterion when attributing cumulative cultural evolution to a given species. Key in identifying cumulative cultural evolution is consideration that innovation has two forms: innovation by modification and innovation by invention (Reader and Laland, 2003). Innovation by (beneficial) modification of an existing trait (or 'ratcheting') is crucial for cumulative culture (Carr et al., 2016), while innovation by invention increases the repertoire of cultural traits (Dean et al., 2014) resulting in cultural evolution (or change) but not cumulative cultural evolution. Here, we will refer to cultural evolution if there is evidence for social learning in the spread of a new behavioural trait in a substantial portion of a group/population (Lamon et al., 2018, Mesoudi and Thornton, 2018).

\section{Drivers of cultural evolution in non-human cultures}

Human landmark behavioural innovations have often correlated with significant ecological changes (e.g., Potts, 2013, Vrba, 1985, Potts, 1996, de Menocal, 2011, Trauth et al., 2005), suggesting that the latter may drive cultural evolution. Similarly, current day human-induced rapid environmental changes can, despite their usually devastating effects on wild animals (see above), also foster behavioural variation, and thus potentially also cultural change. To innovate is to potentially maximise exploitable resources to increase the efficacy of one's behaviour and circumvent novel challenges or threats (Reader and Laland, 2003). Thus innovations (and potential subsequent cultural change) can arise due to 'necessity' mediated by variation in environmental pressures, leading to a reduction in resource availability and animals investigating alternative resources when necessary (Gruber et al. 2016, Lee and Moura, 2015, Grund et al., 2019). Likewise, innovations often arise due to 'opportunity': e.g., innovations may be fostered by frequent exposure to certain substrates and importantly, by exposure to novel stimuli (Luncz et al. 2017, Spagnoletti et al., 2012, Koops et al., 2014). Humans can play a key role for both 'opportunity' and 'necessity' in providing new opportunities or limiting them. Indeed, human impact often leads wild animals to be exposed to novel stimuli, which is a potent catalyst of inovations but a rare event under natural conditions (van Schaik et al., 2016). For example, the recent introduction of oil-palm (Elaeis guineensis) nuts provided the 'opportunity' for long-tailed macaques (Macaca fascicularis) to develop nut-cracking behaviour from habitual cracking of hard-shelled marine invertebrates within roughly a decade (Luncz et al., 2017). Elsewhere, in a comparison of crops consumed by chimpanzees at two sites with differing histories of exposure to agriculture (Bossou in Guinea, and Bulindi in Uganda), chimpanzees showed increased foraging adaptations to cultivated landscapes over time, with crop selection by chimpanzees gradually becoming less selective and including more non-fruits such as underground storage organs and pith (McLennan and Hockings, 2014). In addition, intrinsic factors such as personality (Brosnan and Hopper, 2014) or the ability to overcome neophobia (Forss et al., 2017) also interact with these ecological correlates, leading both extrinsic and intrinsic factors to influence the likelihood of innovation in some individuals, and the potential for cultural change if the new behavioural variant is 
learned by the individual and subsequently copied by others (see Carr et al., 2016 for a review).

Human-induced changes in social behaviour in animals may also impact culture by influencing the grouping patterns, and general social behaviour of animals towards one another. For example, in West Africa, chimpanzee party sizes did not differ when foraging on wild resources and human crops. However, likely due to the need to survey potential threats from humans, party cohesiveness during crop foraging was greater than wild resource foraging (Hockings et al., 2012). This increased cohesiveness leads animals to spend more time in proximity to one another, which could foster the spread of novel behaviours and lead to new cultural traditions within a group. However, human pressure can also force individuals to migrate to survive, potentially leading to further conflicts with conspecifics, humans and other non-human species (e.g., Meric de Bellefon, 2017; Table 1). Forest fragmentation and human infrastructure can result in the fragmentation of animal groups and displacement of individuals which may reduce the transmission of cultural variants as they spread among close associates (Lamon et al., 2017). Likewise, birds and cetaceans often react to human-produced noise by reducing their singing patterns (Nowacek et al., 2007, Davidson et al., 2017), a particular threat to vocal cultures (Slater, 1986, Garland et al., 2017). Thus human activities can potentially disorganise the social complexity of animal societies leading to the loss of cultural behaviour (van Schaik, 2002). Nevertheless, immigrant individuals may also constitute 'cultural vectors', who introduce new innovations and diversify local cultures (Mörchen et al., 2017, Biro et al., 2003, O’Malley et al., 2012, Luncz and Boesch, 2014, Luncz et al., 2015), potentially buffering against human impacts.

Cultural change in animals can be usefully viewed through the lens of niche construction (NC) whereby modifications to the environment where a species lives, as a result of their own or another species' activities, impact on the evolution of a species' behaviour or biology (Odling-Smee et al., 2003). Cultural niche construction (CNC) refers to significant feedback loops between innovations that become cultural and modifications of an organism's environment (Odling-Smee et al., 2003). Humans may drive the evolution of animal cultures through two types of NC (Day et al., 2003). Perturbational NC refers to individuals actively changing the environment through their actions or responding to an environment altered by other species. Two textbook examples in the animal cultural literature, milk bottle opening in parids (Fisher and Hinde, 1949) and food washing in Japanese macaques (Kawai, 1965), describe cases of behavioural adaptations to novel food sources (a perturbation representing an innovation due to 'opportunity') provided by humans that subsequently spread through populations (but see Galef, 1992). Relocatory NC refers to cases where individuals actively move in space, exposing themselves to different environmental factors. A textbook example for Relocatory NC is that of black rats (Rattus rattus) that, due to human deforestation of oak forests in Israel in the early 20th century, were forced (innovation due to 'necessity') to relocate to relatively sterile pine forests where they thrived due to the new cultural trait of pine cone processing to extract and consume the seeds (Terkel, 1996).

\section{Can flexible behavioural adaptations to human activity in non-humans be considered cultural?}

It is essential to differentiate between adaptations that have the potential to be cultural from those that do not. First, it is important to stress that cultural change involves behavioural flexibility or phenotypic plasticity on the part of the individual innovator of the change (Reader and Laland, 2003), but also on the part of those who subsequently socially learn and adopt the new trait (see Harrison and Whiten, 2018 for a review). A change becomes cultural when it eventually spreads to the majority of a group, becoming part of their behavioural portfolio through a diversity of social processes (Whiten et al., 2009, Laland and Hoppitt, 2003, Hoppitt and Laland, 2008) and has longevity across generations (McGrew, 2004, Fragaszy and Perry, 2003). However, an obvious problem with the latter proposal is that human disturbance is often too recent compared with the lifespan of a species, for one to define many changes as fitting this criterion. Nevertheless, evidence of social transmission of a given behaviour between age classes (e.g., Fig. 1) is already a strong indicator of the potential for subsequent transmission and

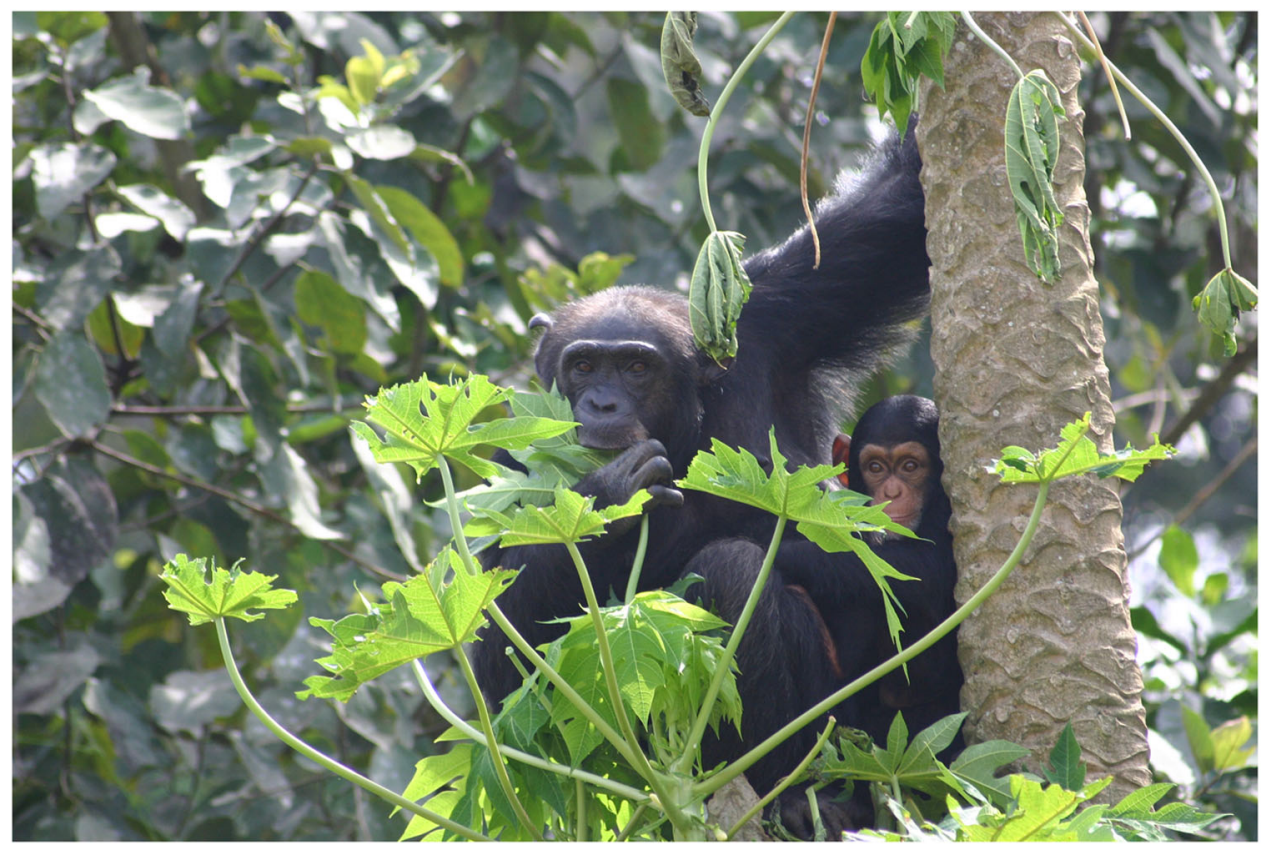

Fig. 1 Mother and infant chimpanzees, Jire and Joya, feeding on papaya (Carica papaya) leaf illustrating cross-generation crop-foraging in Bossou, Guinea (photo taken by K.Hockings) 
fulfilment of stricter criteria for tradition formation. For example, while the Sebitoli chimpanzees' night crop-foraging is mostly led by adult males (Krief et al., 2014), younger individuals participate in this behaviour, making it likely that night time crop-foraging will be passed on to the next generation, even when the founder generation has disappeared. The same applies to other behaviours such as the ingestion of fermented raffia sap by chimpanzees at Bossou in Guinea whereby all age and sex classes use leaf tools, often co-feeding, to access this human resource (Hockings et al., 2015b). In contrast, a behavioural adaptation to human activities that is exhibited by some or most members of a given group may not automatically be associated with social learning because its distribution may represent independent discovery by each group member (Bandini and Tennie, 2017). For example, the concurrent availability of provisioned food and temple visitors (more specifically humans with long hair) appears to have led to the innovation of dental flossing in long-tailed macaques but, although it is a common behaviour in the group, there is no definitive evidence that the behaviour has spread socially (Watanabe et al., 2007, but see Masataka et al., 2009). Similarly, house or trash raiding observed in many species in close proximity to humans, such as chacma baboons (Papio ursinus) in South Africa (Fehlmann et al., 2017), appears unlikely to require social learning.

Table 1 provides examples of current behavioural changes in NHPs, which were induced by anthropogenic activities and likely to be cultural or to become cultural in the near future. To qualify for inclusion examples had to fulfil two criteria: there had to be evidence that (i) the trait belonged to the cultural repertoire of the species in the wild (i.e., being socially transmitted, ideally between age classes, or demonstrating longevity beyond the founder(s), although for some examples such requirement may not be fulfilled because of the recent appearance of the behaviour) and, (ii) that the observed change is attributable to human influence. For some of our examples (those denoted with an 'a' in Table 1), there is no direct connection between the evidence for social learning presented on the one hand, and the behavioural adaptation to human influence on the other, meaning these examples are relatively speculative. However, these examples were included in consideration of the fact that if no action is taken to study how animal cultures are influenced by human activities, populations exhibiting these potential cultural adaptations may well have disappeared by the time they are considered cultural (e.g., Sapolsky and Share, 2004). Indeed, clear unequivocal evidence that behavioural variants belong to the cultural repertoire of a species are notoriously difficult to obtain (Hobaiter et al., 2014, Allen et al., 2013, Hirata et al., 2001). The goal here is to identify behavioural adaptations that have the potential to be cultural responses to human activities and to spur further debate and research regarding the topic.

The examples in Table 1 can be linked to three major types of human influence, as they can be a reaction to: first, the mere presence of humans in the environment; second, the introduction of novel substrate by humans; and third, the human destruction of the environment (variously resulting in perturbational or relocationary NC due to opportunity or necessity). In agreement with previous analyses of innovation behaviour in NHPs (Reader and Laland, 2002), the majority (69\%) of our recorded cases ( 9 of 13 cases) concern behavioural changes in the foraging domain. Of the 16 behavioural adaptations recorded within these 13 cases, $25.0 \%$ (4 of 16) represent a decrease or loss of behaviour (e.g., a decrease in stone tool use in long-tailed macaques, Gumert et al., 2013), 37.5\% (6 of 16) represent a modification to an existing behaviour (e.g., chimpanzee nest manufacture using introduced plant species, McCarthy et al., 2017), and 37.5\% (6 of 16) a novel behaviour (e.g., development of fish eating in Japanese macaques, Watanabe, 1989).

The low number of cases so far may be due to the difficulty with which wild animal cultural traits are identified (Kendal et al., 2010b). The drawbacks of the exclusion method are known (Laland and Janik, 2006): it can be hard to gather data from enough groups to ascertain that a given variant is truly cultural; and social learning may be involved in the spread of a behaviour pattern even where its distribution is also influenced by ecology. A prime example of this type-II error is found in variations in diet, which may be both driven by ecology but also culture (Jaeggi et al., 2010). This is important as the inclusion of humanintroduced trees or crops into the diet (McLennan and Hockings, 2014) are likely to constitute a major part of NHP behavioural responses to humans. Despite its known flaws, the exclusion method allows the identification of potential cultural traits by a simple and comparative ethological approach (Laland et al., 2009). In addition, alternative statistical methods that directly assess the presence of social learning in the transmission of a trait can be used when possible (Farine et al., 2015, Kendal et al., 2010b). Nevertheless, their application to non-intentional/nonexperimental human-induced environmental change (e.g., Hobaiter et al., 2014) relies on serendipitously observing a population undergoing change. Here, paying closer attention to the responses of non-human animals to human induced change, especially those from long-term research sites, will provide the opportunity to gather the information necessary to infer evidence for cultural change (Box 1). Finally, correlational approaches that assess both the degree to which animal populations are exposed to human disturbance and the extent by which a possible cultural repertoire has varied over time will be instrumental to determine how the type and degree of human-provoked disturbance might modify species' cultural repertoires. Such approaches, however, necessitate knowledge of the extent of a given population's repertoire, which can often take several decades (Boesch and Boesch-Achermann, 2000). Therefore, this approach will be limited to the small (but growing) number of well-documented populations in NHPs and other species.

\section{Humans as both threats to and catalysts of cultural change in animals}

The working hypothesis of this paper has been that humans, both through their direct and indirect actions, must be considered a potential force for cultural evolution in wild animals. Table 1 presents tentative examples in NHPs, which may be good candidates for cultural behaviours whose appearance or modification is currently being influenced by human activities. In particular, human activities may lead to the reduction of displays of cultural traits (Kühl et al., 2019), but also to their modification or to the invention of novel behaviour that has the potential to become cultural. On the one hand, the examples we present in this study (although not exhaustive) suggest that the reduction of observed cultural behaviour is possibly linked to loss of opportunity, both in terms of the available ecological niche, but also of social opportunities for learning. On the other hand, new opportunities for social learning, particularly through the introduction of novel and edible foods in the environment can lead to the establishment of new potential traditions in animals. Our catalogue is by no means exhaustive and one reason for our limited sample size is that animals must exhibit behavioural flexibility and their capacity to learn from each other be documented in the first place to be considered capable of cultural change. For example, while many species exhibit 'automatic' (or genetically driven) tool use (Shumaker et al., 2011), only a limited number of species exhibit the flexibility that may allow them to adapt their tool use 


\section{Box 1: Types of human disturbances and expected changes in animal cultural behaviour leading to cultural evolution}

\section{Type of disturbance}

Human presence

Introduced food items

Habitat alteration

Methods to isolate whether change is cultural

Evidence for social learning/against

individual learning

\section{Expected changes in cultural behaviour}

Decrease in frequency of cultural behaviour display when humans/human activities are in the vicinity Innovation (and spread) of novel behaviour in response to human provided opportunities Introduction of a novel human-introduced food item in the diet

Social adaptation to consumption of human-introduced food to avoid conflicts with humans Loss of natural cultural behaviour between generation as introduced easy-to-easy access resources become part of the diet vs. development of new cultural behaviour because of more time afforded by more relax feeding pressure

Use of introduced plants for other purposes (e.g., nest-building)

Raise of frequency of novel socially-transmitted behaviour at provisioning site Direct impact on health that prevents animals from displaying their cultures

Decrease in frequency of cultural behaviour because of the disappearance of the exploited resource

1) No multiple individual innovation (e.g., Zone of Latent Solution)

2) indirect evidence for social learning (e.g., Method of exclusion)

3) Direct evidence for social learning (social networks and/or captive studies)

4) Ontogenetic evidence for spread across age-classes

5) Longitudinal evidence for longevity of trait beyond founders

See for references: (1) Bandini and Tennie, 2017, PeerJ. (2) Whiten et al., 1999, Nature. (3) Hoppitt and Laland, 2011, American Journal of Primatology. (4) Lamon et al., 2017, Science Advances. (5) Hirata et al., 2001 Primate origins of human cognition and behaviour.

culturally to changes in their environment in the short term (Call, 2013, Jacobson and Hopper, 2019). In this respect it would be particularly interesting to study the types of behavioural adaptation shown by other famed flexible tool-users such as corvids (e.g. New Caledonian crows (Corvus moneduloides, Hunt and Gray, 2003, Rutz et al., 2010) or jackdaws (Corvus monedula, Greggor et al., 2016)). It is also important to stress that most of our examples are cases of adoption of new food sources (Reader and Laland, 2002), which may be less cognitively demanding than tool use, and thus require less social learning (Kendal et al., 2009). For these examples, as well as others found in the non-primate literature (e.g., Diaz Lopez, 2012), in order to show cultural evolution researchers will require evidence that an apparent behavioural tradition is socially transmitted (Jaeggi et al., 2010) rather than resulting from individual learning (Bandini and Tennie, 2017). Nevertheless, it is likely that more examples will be uncovered as more species are sampled, and more behavioural patterns receive scientific scrutiny. For example, the recent focus on the cultural dimension of travel routes in birds and ungulates (Sasaki and Biro, 2017, Jesmer et al., 2018) may provide additional examples of how animal knowledge-and culture-is being influenced or threatened by human activities. Finally, based on current information (Table 1) and attention to anthropogenic disturbance, it is appropriate to raise the question of human impact on animal cultures for the following reasons:

Humans are catalysers of cultural change. Humans are not the only driver of cultural change in animals. For example, a natural disaster may force animal populations to migrate to a novel environment, leading to the adoption of new behavioural traditions. However, this paper has argued that human activities, particularly in recent decades, have increased the likelihood of cultural changes, by directly tampering with the natural environment of animals. By physically modifying the environment where wild animals live, for instance by installing snares or encroaching on the forest, humans cause animals to develop behavioural counter strategies (e.g., snare deactivation techniques, Ohashi and Matsuzawa, 2010). Where these behaviours come to characterise certain groups compared with other less-impacted groups of the same species, and there is suggestive evidence that the distribution of the behaviour involves social learning, we may claim human induced changes to wild animal cultures. Indeed, most of our documented behavioural adaptations constitute novel behaviours, either through innovations by invention or by modification, that have the potential to be considered as new cultural variants. Such direct and indirect influence of humans therefore cannot be ignored when analysing culture in wildlife.

Human activities directly threaten animal cultural behaviour. The degree to which the behavioural flexibility of animals will enable them to survive in our rapidly changing world remains an open question. In a recent article, chimpanzee researchers found that human disturbance correlated with less observed behavioural diversity, suggesting that human presence directly threatens cultural diversity in chimpanzees (Kühl et al., 2019). The rapid pace of anthropogenic environmental change suggests that unless drastic measures are taken, all wild animal populations will be forced to respond to some form of human disturbance soon. The threat to animal cultures is therefore unquestionable and must be incorporated into conservation policy (Brakes et al., 2019).

\section{Conclusions}

The study of animal cultural evolution is still in its infancy yet we currently have a unique opportunity to study and understand its drivers. Some species display the behavioural flexibility to cope with or even take advantage of novel ecological opportunities, although this may only happen out of necessity due to increased cohabitation with humans. For various reasons, however, innovations may not always spread or be maintained in subsequent generations. We predict that the higher the impact of humans on a population's habitat, the more existing behavioural traditions may be lost because of human pressure; but, concurrently, the higher this impact, the more (potentially cultural) behavioural adaptations unique to that population should be observed as a direct result of exposure to novel anthropogenic stimuli. Nevertheless, there is also a clear risk of uniformization and loss of cultures as all populations are likely to face very similar threats from humans. Finally, another prediction is that behavioural adaptations will only spread, within and between populations, if social conditions are adequate, that is, if human disturbance does not fragment the population or lead to increased stress levels (Boogert et al., 2013) that might hinder social learning. To 
operationalise these predictions, researchers will need evidence of human activities, as well as evidence of behavioural change in animals that may directly or indirectly result from these activities and to determine whether social learning is involved. As demonstrated in this paper, change in social structure resulting from human activities can directly influence the cohesiveness of animal groups, either increasing it and thus increasing opportunities for social learning, or not. Quantifying the instances (either ancient or new) for cultural behaviours that result directly from human activities will allow us to determine the impact of humans on animal cultural evolution.

As anthropogenic environmental change appears able to induce cultural change stemming from innovations by modification, one may also see an increase in the, hitherto sparse (Dean et al., 2014), evidence of cumulative cultural evolution in wild NHPs. This 'forced' modification of cultural traits differs from the spontaneous motivation to modify the complexity or efficiency of a trait associated with current human cumulative culture. However, it mirrors the beginnings of our own cumulative cultural abilities which were likely a product of altered selection pressures resulting from expansion into new environments (Stiner and Kuhn, 2006) and demographic changes (Derex and Boyd, 2016) during our evolutionary history. Studying human-induced animal cultural evolution, in an epoch some term the Anthropocene (Lewis and Maslin, 2015), may thus shed light on our own cultural evolution.

\section{Data availability}

Data sharing not applicable to this article as no datasets were generated or analysed during the current study.

Received: 25 February 2019 Accepted: 20 May 2019

Published online: 18 June 2019

\section{References}

Allen J, Weinrich M, Hoppitt W, Rendell L (2013) Network-based diffusion analysis reveals cultural transmission of lobtail feeding in humpback whales. Science 340:485-488

Aplin LM, Farine DR, Morand-Ferron J, Cockburn A, Thornton A, Sheldon BC (2015) Experimentally induced innovations lead to persistent culture via conformity in wild birds. Nature 518:538-541

Ancrenaz et al. (2014) Of Pongo, palms and perceptions: a multidisciplinary assessment of Bornean orang-utans Pongo pygmaeus in an oil palm context. Oryx 49(3):465-472

Bandini E, Tennie C (2017) Spontaneous reoccurrence of "scooping", a wild tooluse behaviour, in naive chimpanzees. PeerJ 5:e3814

Barrett LP, Stanton LA, Benson-Amram S (2019) The cognition of 'nuisance' species. Anim Behav 147:167-177

Bates LA, Sayialel KN, Njiraini NW, Moss CJ, Poole JH, Byrne RW (2007) Elephants classify human ethnic groups by odor and garment color. Curr Biol 17 (22): 1938-1942

Beever EA, Hall LE, Varner J, Loosen AE, Dunham JB, Gahl MK, Smith FA, Lawler JJ (2017) Behavioral flexibility as a mechanism for coping with climate change. Front Ecol Environ 15(6):299-308

Biro D, Inoue-Nakamura N, Tonooka R, Yamakoshi G, Sousa C, Matsuzawa T (2003) Cultural innovation and transmission of tool use in wild chimpanzees: evidence from field experiments. Anim Cogn 6:213-223

Boesch C, Boesch-Achermann H (2000) The chimpanzees of the Taï forest: behavioural ecology and evolution. Oxford University Press, Oxford

Boogert NJ, Zimmer C, Spencer KA (2013) Pre- and post-natal stress have opposing effects on social information use. Biol Lett 9(2):20121088

Boyd R, Richerson PJ (1985) Culture and the evolutionary process. University of Chicago Press, Chicago

Brakes P, Dall SRX, Aplin LM, Bearhop S, Carroll EL, Ciucci P, Fishlock V, Ford JKB, Garland EC, Keith SA, McGregor PK, Mesnick SL, Noad MJ, di Sciara GN, Robbins MM, Simmonds MP, Spina F, Thornton A, Wade PR, Whiting MJ, Williams J, Rendell L, Whitehead H, Whiten A, Rutz C (2019) Animal cultures matter for conservation. Science 363(6431):1032-1034
Brosnan SF, Hopper LM (2014) Psychological limits on animal innovation. Anim Behav 92:325-332

Brotcorne et al. (2017) Intergroup variation in robbing and bartering by long-tailed macaques at the Uluwatu Temple (Bali, Indonesia). Primates 58:505-516

Call J (2013) Three ingredients for becoming a creative tool user. In: Sanz CM, Call J, Boesch C (eds) Tool use in animals: cognition and ecology. Cambridge University Press, Cambridge, p 3-20

Candolin U, Wong BBM (eds) (2012) Behavioural responses to a changing world: mechanisms and consequences. Oxford University Press, Oxford

Carr K, Kendal RL, Flynn EG (2016) Eureka!: what is innovation, how does it develop, and who does it? Child Dev 87:1505-1519

Charnov EL, Berrigan D (1993) Why do female primates have such long lifespans and so few babies? or Life in the slow lane. Evolut Anthropol 1(6):191-194

Cheyne SM (2010) Behavioural Ecology of Gibbons (Hylobates albibarbis) in Degraded Peat-Swamp Forest. In: Gursky S, Supriatna J (eds) Indonesian Primates. Developments in Primatology: Progress and Prospects. Springer, New York, NY, pp. 121-156

Davidson BM, Antonova G, Dlott H, Barber JR, Francis CD (2017) Natural and anthropogenic sounds reduce song performance: insights from two emberizid species. Behav Ecol 28(4):974-982

Day RL, Laland KN, Odling-Smee J (2003) Rethinking adaptation-the niche-construction perspective. Perspect Biol Med 46(1):80-95

de Menocal PB (2011) Climate and human evolution. Science 331:540-541

Dean LG, Vale GL, Laland KN, Flynn E, Kendal RL (2014) Human cumulative culture: a comparative perspective. Biol Rev 89:284-301

Derex M, Boyd R (2016) Partial connectivity increases cultural accumulation within groups. PNAS 113:2982-2987

Diaz Lopez B (2012) Bottlenose dolphins and aquaculture: interaction and site fidelity on the north-eastern coast of Sardinia (Italy). Mar Biol 159:2161-2172

Farine DR, Aplin LM, Sheldon BC, Hoppitt W (2015) Interspecific social networks promote information transmission in wild songbirds. Proc R Soc B 282:2804

Fehlmann G, O’Riain MJ, Kerr-Smith C, Hailes S, Luckman A, Shepard ELC, King AJ (2017) Extreme behavioural shifts by baboons exploiting risky, resourcerich, human-modified environments. Sci Rep 7(1):15057

Fisher J, Hinde RA (1949) The opening of milk bottles by birds. Brit Birds 42:347-357

Forss SIF, Koski SE, van Schaik CP (2017) Explaining the paradox of neophobic explorers: the social information hypothesis. Int J Primatol 38(5):799-822

Fragaszy DM, Perry S (eds) (2003) The biology of traditions. Cambridge University Press, Cambridge

Galef BG (1992) The question of animal culture. Hum Nat 3(2):157-178

Garland EC, Rendell L, Lamoni L, Poole MM, Noad MJ (2017) Song hybridization events during revolutionary song change provide insights into cultural transmission in humpback whales. PNAS 114:7822-7829

Goodall J (1973) Cultural elements in a chimpanzee community. In: Menzel E (ed) Precultural primate behavior. Karger, Basel, p 138-159

Greggor AL, Clayton NS, Phalan B, Thornton A (2014) Comparative cognition for conservationists. Trends Ecol Evol 29(9):489-495

Greggor AL, McIvor GE, Clayton NS, Thornton A (2016) Contagious risk taking: social information and context influence wild jackdaws' responses to novelty and risk. Sci Rep 6:27764

Gruber T, Potts K, Krupenye C, Byrne M-R, Mackworth-Young C, McGrew WC, Reynolds V, Zuberbühler K (2012) The influence of ecology on chimpanzee cultural behaviour: a case study of five Ugandan chimpanzee communities. J Comp Psychol 126:446-457

Gruber (2013) Historical hypotheses of chimpanzee tool use behaviour in relation to natural and human-induced changes in an East African rain forest. Revue de Primatologie 5:66

Gruber T, Zuberbühler K, Neumann C (2016) Travel fosters tool use in wild chimpanzees. eLife https://doi.org/10.7554/eLife.16371

Gruber et al. (2009) Wild chimpanzees rely on cultural knowledge to solve an experimental honey acquisition task. Curr Biol 19:806-1810

Grund C, Neumann C, Zuberbühler K, Gruber T (2019) Necessity creates opportunities for Chimpanzee tool use. Behav Ecol. arz062, https://doi.org/ 10.1093/beheco/arz062

Gumert MD, Hamada Y, Malaivijitnond S (2013) Human activity negatively affects wild stone tool-using Burmese long-tailed macaques Macaca fascicularis aurea in Laemson National Park, Thailand. Oryx 2013:1-9. 14 August

Harrison RA, Whiten A (2018) Chimpanzees (Pan troglodytes) display limited behavioural flexibility when faced with a changing foraging task requiring tool use. PeerJ 6:e4366

Hicks CT, Roessingh P, Menken SBJ (2013) Impact of humans on long-distance communication behaviour of Eastern chimpanzees (Pan troglodytes schweinfurthii) in the Northern Democratic Republic of Congo. Folia Primatol 84:135-156

Hirata S, Watanabe K, Kawai M (2001) "Sweet-potato washing" revisited. In: Matsuzawa T (ed) Primate origins of human cognition and behaviour. Springer, Tokyo, p 487-508 
Hobaiter C, Poisot T, Zuberbühler K, Hoppitt W, Gruber T (2014) Social network analysis shows direct evidence for social transmission of tool use in wild chimpanzees. PLoS Biol 12(9):e1001960

Hockings KJ, Anderson JR, Matsuzawa T (2012) Socioecological adaptations by chimpanzees, Pan troglodytes verus, inhabiting an anthropogenically impacted habitat. Anim Behav 83:801-810

Hockings KJ, McLennan MM, Carvalho S, Ancrenaz M, Bobe R, Byrne RW, Dunbar RIM, Matsuzawa T, McGrew WC, Williams EA, Wilson ML, Wood B, Wrangham RW, Hill CM (2015a) Apes in the Anthropocene: Flexibility and survival. Trends Ecol Evol 30:215-222

Hockings KJ, Bryson-Morrison N, Carvalho S, Fujisawa M, Humle T, McGrew WC, Nakamura M, Ohashi G, Yamanashi Y, Yamakoshi G, Matsuzawa T (2015b) Tools to tipple: ethanol ingestion by wild chimpanzees using leafsponges. R Soc Open Sci 2(6):150150

Hoppitt W, Laland KN (2011) Detecting social learning using networks: a users guide. Am J Primatol 73:834-844

Hoppitt WJE, Laland KN (2008) Social processes influencing learning in animals: a review of the evidence. Adv Study Behav 38:105-165

Hunt GR, Gray RD (2003) Diversification and cumulative evolution in New Caledonian crow tool manufacture. Proc R Soc B 270:867-874

Imanishi K (1952) The evolution of human nature. In: Imanishi K (ed) Ningen. Mainichi-shinbunsha, Tokyo, p 36-94. (Japanese)

Jacobson SL, Hopper LM (2019) Hardly habitual: chimpanzees and gorillas show flexibility in their motor responses when presented with a causally-clear task. PeerJ 7:e6195-e6195

Jaeggi A, Dunkel L, van Noordwijk MA, Wich SA, Sura AAL, van Schaik CP (2010) Social learning of diet and foraging skills by wild immature Bornean orangutans: Implications for culture. Am J Primatol 72:62-71

Jesmer BR, Merkle JA, Goheen JR, Aikens EO, Beck JL, Courtemanch AB, Hurley MA, McWhirter DE, Miyasaki HM, Monteith KL, Kauffman MJ (2018) Is ungulate migration culturally transmitted? Evidence of social learning from translocated animals. Science 361(6406):1023-1025

Kawai M (1965) Newly-acquired pre-cultural behavior of the natural troop of Japanese monkeys on Koshima islet. Primates 6(1):1-30

Kendal RL, Custance D, Kendal JR, Vale G, Stoinski T, Rakotomalala NI, Rasaminanana H (2010a) 'Evidence for social learning in wild lemurs (Lemur catta)'. Learn Behav 38:220-234

Kendal RL, Galef BG, van Schaik CP (2010b) Capturing social learning in natural contexts: Methodological insights and implications for culture. Learn Behavior 8(3):187-336

Kendal RL, Kendal JR, Hoppitt WJE, Laland KN (2009) Identifying social learning in animal populations: a new 'option-bias' method. PLoS ONE 4(8):e654

Koda et al. (2013) Possible role of mother-daughter vocal interactions on the development of species-specific song in gibbons. PLoS ONE 8(8):e71432

Koops K, Visalberghi E, van Schaik CP (2014) The ecology of primate material culture. Biol Lett 10:20140508

Krief S, Cibot M, Bortolamiol S, Seguya A, Krief J-M, Masi S (2014) Wild chimpanzees on the edge: nocturnal activities in croplands. PLoS ONE 9(10): e109925

Krützen M, van Schaik C, Whiten A (2007) The animal cultures debate: response to Laland and Janik. Trends Ecol Evol 22(1):6

Kühl HS, Boesch C, Kulik L et al. (2019) Human impact erodes chimpanzee behavioral diversity. Science 363(6434):1453-1455

Laland KN, Galef BG(eds) (2009) The question of animal culture. Harvard University Press, Cambridge

Laland KN, Hoppitt WJE (2003) Do animals have culture? Evolut Anthropol 12 (3):150-159

Laland KN, Janik VM (2006) The animal cultures debate. Trends Ecol Evol 21 (10):542-547

Laland KN, Kendal JR, Kendal RL (2009) Animal culture: problems and solutions. In:Laland KN, Galef BG (eds) The question of animal culture. Harvard University Press, Cambridge

Lamon N, Neumann C, Gier J, ZUberbühler K, Gruber T (2018) Wild chimpanzees select tool material based on efficiency and knowledge. Proc R Soc B 285:20181715

Lamon N, Neumann C, Gruber T, Zuberbühler K (2017) Kin-based cultural transmission of tool use in wild chimpanzees. Sci Adv 3(4):e1602750

Langergraber KE, Boesch C, Inoue E, Inoue-Murayama M, Mitani JC, Nishida T, Pusey A, Reynolds V, Schubert G, Wrangham RW, Wroblewski E, Vigilant, L (2010) Genetic and 'cultural' similarity in wild chimpanzees. Proc R Soc B 278:408-416

Leca et al. (2008) Food provisioning and stone handling tradition in Japanese macaques: a comparative study of ten troops. Am J Primat 70:803-813

Lee PC, Mour a ACA (2015) Necessity, unpredictability and opportunity: an exploration of ecological and social drivers of behavioural innovation. In: Kaufman AB, Kaufman JC (eds) Animal creativity and innovation. Elsevier, London, p 317-329

Lewis SL, Maslin MA (2015) Defining the anthropocene. Nature 519:171
Luncz LV, Boesch C (2014) Tradition over trend: neighboring chimpanzee communities maintain differences in cultural behavior despite frequent immigration of adult females. Am J Primatol 76:n/a-n/a

Luncz LV, Svensson MS, Haslam M, Malaivijitnond S, Proffitt T, Gumert M (2017) Technological response of wild Macaques (Macaca fascicularis) to anthropogenic change. Int J Primatol 38:872-880

Luncz LV, Wittig RM, Boesch C (2015) Primate archaeology reveals cultural transmission in wild chimpanzees (Pan troglodytes verus). Philos Trans R Soc B 370:pii: 20140348

Matsuzawa T, Yamakoshi G (1996) Comparison of chimpanzee material culture between Bossou and Nimba, West Africa. Reaching into thought: the mind of the great apes. Russon, AE, Bard KA (eds) Cambridge University Press, Cambridge, p. 211-232

Marnocha E, Pollinger J, Smith TB (2011) Human-induced morphological shifts in an island lizard. Evolut Appl 4(2):388-396

Masataka N, Koda H, Urasopon N, Watanabe K (2009) Free-ranging macaque mothers exaggerate tool-using behavior when observed by offspring. PLoS ONE 4(3):e4768

McCarthy MS, Lester JD, Stanford CB (2017) Chimpanzees (Pan troglodytes) flexibly use introduced species for nesting and bark feeding in a humandominated habitat. Int J Primatol 38(2):321-337

McGrew WC (2004) The cultured chimpanzee: reflections on cultural primatology. Cambridge University Press, Cambridge

McLennan MR, Hockings KJ (2014) Wild chimpanzees show group differences in selection of agricultural crops. Sci Rep 4:5956

McLennan MR, Spagnoletti N, Hockings KJ (2017) The implications of primate behavioral flexibility for sustainable human-primate coexistence in anthropogenic habitats. Int J Primatol 38(2):105-121

Meric de Bellefon J (2017) Consequences of the forest fires for the diet, ranging behaviors, and social interactions of wild female Bornean orangutans (Pongo pygmaeus wurmbii). unpublished thesis, University of Zurich

Mesoudi A, Thornton A (2018) What is cumulative cultural evolution? Proc R Soc B 285:20180712

Möbius Y, Boesch C, Koops K, Matsuzawa T, Humle T (2008) Cultural differences in army ant predation by West African chimpanzees? A comparative study of microecological variables. Anim Behav 76:37-45

Mörchen J, van Noordwijk M, van Schaik C (2017) Learning from the immigrants: dispersing orangutan males as cultural vectors. Folia Primatol 88:129

Nowacek DP, Thorne LH, Johnston DW, Tyack PL (2007) Responses of cetaceans to anthropogenic noise. Mammal Rev 37(2):81-115

O'Malley RC, Wallauer W, Murray CM, Goodall J (2012) The appearance and spread of ant fishing among the Kasekela Chimpanzees of Gombe: a possible case of intercommunity cultural transmission. Curr Anthropol 53(5):650-663

Odling-Smee FJ, Laland KN, Feldman MW (2003) Niche construction: the neglected process in evolution, monographs in population biology. Princeton University Press, Princeton

Ohashi G, Matsuzawa T (2010) Deactivation of snares by wild chimpanzees. Primates 52(1):1-5

Potts R (1996) Evolution and climate variability. Science 273:922-923

Potts R (2013) Hominin evolution in settings of strong environmental variability. Quat Sci Rev 73:1-13

Reynolds et al. (2015) Mineral acquisition from clay by Budongo Forest Chimpanzees. PLoS ONE 10(7):e0134075

Reader SM, Laland KN (2002) Social intelligence, innovation, and enhanced brain size in primates. Proc Natl Acad Sci USA 99:4436-4441

Reader SM, Laland KN (eds) (2003) Animal innovation. Oxford University Press, Oxford

Rutz C, Bluff LA, Reed N, Troscianko J, Newton J, Inger R, Kacelnik A, Bearhop S (2010) The ecological significance of tool use in new Caledonian crows. Science 329(5998):1523-1526

Sanz CM, Call J, Morgan D (2009) Design complexity in termite-fishing tools of chimpanzees (Pan troglodytes). Biol Lett 5:293-296

Sapolsky RM, Share LJ (2004) A pacific culture among wild baboons: its emergence and transmission. PLOS Biol 2(4):534-541

Sasaki T, Biro D (2017) Cumulative culture can emerge from collective intelligence in animal groups. Nat Commun 8:15049

Schofield et al. (2018) Cumulative culture in nonhumans: overlooked findings from Japanese monkeys? Primates 59(2):113-122

Schöning C, Humle T, Möbius Y, McGrew WC (2008) The nature of culture: technological variation in chimpanzee predation on army ants revisited. J Hum Evol 55:48-59

Schuppli C, Forss S, Meulman EJM, Zweifel N, Lee KC, Rukmana E, Vogel ER, van Noordwijk MA, van Schaik CP (2016) Development of foraging skills in two orangutan populations: needing to learn or needing to grow? Front Zool 13 (1):online

Shumaker RW, Walkup KR, Beck BB (2011) Animal tool behavior: the use and manufacture of tools by animals. The Johns Hopkins University Press, Baltimore, MD 
Sih A, Ferrari MCO, Harris DJ (2011) Evolution and behavioural responses to human-induced rapid environmental change. Evolut Appl 4:367-387

Slater PJB (1986) The cultural transmission of bird song. Trends Ecol Evol 1 (4):94-97

Spagnoletti N, Visalberghi E, Verderane MP, Ottoni E, Izar P, Fragaszy D (2012) Stone tool use in wild bearded capuchin monkeys, Cebus libidinosus. Is it a strategy to overcome food scarcity? Anim Behav 83:1285-1294

St Clair JJH, Klump BC, Sugasawa S, Higgott CG, Colegrave N, Rutz C (2018) Hook innovation boosts foraging efficiency in tool-using crows. Nat Ecol Evol 2(3):441-444

Stiner MC, Kuhn SL (2006) Changes in the 'connectedness' and resilience of Paleolithic societies in Mediterranean ecosystems. Hum Ecol 34:693-712

Tagg et al. (2013) Ground night nesting in chimpanzees: New insights from Central chimpanzees (Pan troglodytes troglodytes) in South-East Cameroon. Folia Primatologica 84:362-383

Tan AWY (2017) From play to proficiency: the ontogeny of stone-tool use in coastal-foraging long-tailed macaques (Macaca fascicularis) from a comparative perception-action perspective. J Comparat Psych 131:89-114

Tennie C, Call J, Tomasello M (2009) Ratcheting up the ratchet: on the evolution of cumulative culture. Philos Trans R Soc B 364:2045-2415

Terkel J (1996) Cultural transmission of feeding behavior in the black rat (Rattus rattus). In: Heyes CM, Galef J. BG (eds) Social learning in animals: the roots of culture. Academic Press, San Diego, p 17-47

Tomasello M (1990) 'Cultural transmission in the tool use and communicatory signaling of chimpanzees?'. In: Parker S, Gibson K (eds) "Language" and intelligence in monkeys and apes: comparative developmental perspectives. CUP, Cambridge, p 274-311

Trauth MH, Maslin MA, Deino A, Strecker MR (2005) Late Cenozoic moisture history of east Africa. Science 309:2051-2053

Tucker MA, Böhning-Gaese K, Fagan et al. (2018) Moving in the anthropocene: global reductions in terrestrial mammalian movements. Science 359 (6374):466-469

van Schaik CP (2002) Fragility of traditions: the disturbance hypothesis for the loss of local traditions in orangutans. Int J Primatol 23:527-538

van Schaiket al. (2003) Orangutan cultures and the evolution of material culture. Science 299:102-105

van Schaik CP, Barrickman N, Bastian ML, Krakauer EB, Van Noordwijk MA (2006) Primate life histories and the role of brains. In: Hawkes K, Paine RR (eds) The evolution of human life history. School of American Research Press, Santa Fe, p 127-54

van Schaik CP, Burkart J, Damerius L, Forss SIF, Koops K, van Noordwijk MA, Schuppli C (2016) The reluctant innovator: orangutans and the phylogeny of creativity. Philos Trans R Soc B 371:20150183

Vrba ES (1985) Ecological and adaptive changes associated with early hominid evolution. In:Delson E (ed) Ancestors: the hard evidence. Alan R. Liss, NewYork, p 63-71

Watanabe K (1989) Fish: a new addition to the diet of Koshima monkeys. Folia Primatol 52:124-131

Watanabe K, Urasopon N, Malaivijitnond S (2007) Long-tailed macaques use human hair as dental floss. Am J Primatol 69:940-944
Whitehead H (2010) Conserving and managing animals that learn socially and share cultures. Learn Behav 38:329-336

Whiten A, Goodall J, McGrew WC, Nishida T, Reynolds V, Sugiyama Y, Tutin CEG, Wrangham RW, Boesch C (1999) Cultures in Chimpanzees. Nature 399(6737):682-685

Whiten A, McGrew WC, Aiello LC, Boesch C, Boyd R, Byrne RW, Dunbar RIM, Matsuzawa T, Silk JB, Tomasello M, Van Schaik CP, Wrangham RW (2010) Studying extant species to model our past. Science 327:410

Whiten A, McGuigan N, Marshall-Pescini S, Hopper LM (2009) Emulation, imitation, over-imitation and the scope of culture for child and Chimpanzee. Philos Trans R Soc B 364:2417-2428

Wild S, Krützen M, Rankin RW, Hoppitt WJE, Gerber L, Allen SJ (2019) Longterm decline in survival and reproduction of dolphins following a marine heatwave. Curr Biol 29(7):R239-R240

\section{Acknowledgements}

TG was supported by the Swiss National Science Foundation (grants CR13I1_162720 and P300PA_164678) throughout the writing of this article. We thank Claudio Tennie for comments on earlier drafts of the paper and the participants to the Symposium "Primate cultures: Update and new trends" at the 7th European Federation of Primatology Meeting. We also thank two anonymous reviewers for their useful comments on an earlier version of this manuscript.

\section{Additional information}

Competing interests: The authors declare no competing interests.

Reprints and permission information is available online at http://www.nature.com/ reprints

Publisher's note: Springer Nature remains neutral with regard to jurisdictional claims in published maps and institutional affiliations.

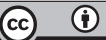

Open Access This article is licensed under a Creative Commons Attribution 4.0 International License, which permits use, sharing adaptation, distribution and reproduction in any medium or format, as long as you give appropriate credit to the original author(s) and the source, provide a link to the Creative Commons license, and indicate if changes were made. The images or other third party material in this article are included in the article's Creative Commons license, unles indicated otherwise in a credit line to the material. If material is not included in the article's Creative Commons license and your intended use is not permitted by statutory regulation or exceeds the permitted use, you will need to obtain permission directly from the copyright holder. To view a copy of this license, visit http://creativecommons.org/ licenses/by/4.0/

(c) The Author(s) 2019 